\title{
Public('s) nutrition
}

\author{
Micheline Beaudry ${ }^{1, *}$ and Hélène Delisle ${ }^{2}$ \\ 'Département des sciences des aliments et de nutrition, Faculté des sciences de l'agriculture et de l'alimentation, \\ Université Laval, Québec, Canada, GIK 7P4: ${ }^{2}$ WHO Collaborating Centre on Nutrition Changes and Development, \\ Département de nutrition, Faculté de médecine, Université de Montréal, Montréal, Québec, Canada
}

\begin{abstract}
Objective: To promote the new field of 'public nutrition' as a means to address, in a more efficient, sustainable and ethical manner, the world-wide epidemic of malnutrition - undernutrition and specific nutrient deficiencies, and also obesity and other nutrition-related chronic diseases.

Strategy: Grounded in the health promotion model, public nutrition applies the population health strategy to the resolution of nutrition problems. It encompasses 'public health nutrition', 'community nutrition' and 'international nutrition' and extends beyond them. It fits within the conceptual framework of 'the new nutrition science' and is an expression of this reformulated science in practice. Its fundamental goal is to fulfil the human right to adequate food and nutrition. It is in the interest of the public, it involves the participation of the public and it calls for partnerships with other relevant sectors beyond health. Public nutrition takes a broader view of nutritional health, addressing the three interrelated determinant categories of food systems and food security; food and health practices; and health systems. It assesses and analyses how these influence the immediate determinants that are dietary intake and health status so as to direct action towards effective progress. To further enhance the relevance and effectiveness of action, public nutrition advocates improved linkages between policies and programmes, research and training. A renewed breed of professionals for dietetics and nutrition, trained along those lines, is suggested. Conclusion: There is a critical need to develop new knowledge, approaches and skills to meet the pressing nutrition challenges of our times.
\end{abstract}

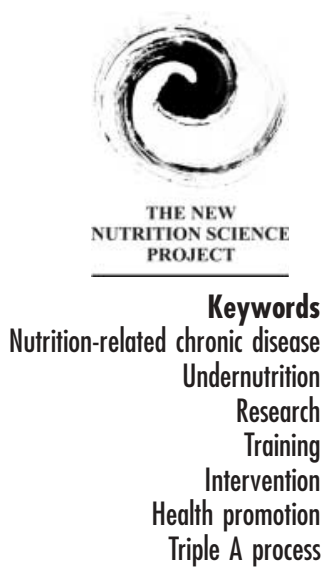

The relevance of nutrition to the major health problems afflicting populations in both high- and low-income countries is now prominent ${ }^{1-4}$. Whether malnutrition (which may also be termed dysnutrition) is a problem of insufficiency, excess or imbalance, it has reached unprecedented levels. The costs to society and to individuals are staggering ${ }^{1,4}$. This situation - akin to a global epidemic - has led to increasing calls for action at all levels. The multifactorial nature of these problems is well accepted, as is the need to involve a number of sectors and disciplines outside health to resolve them, especially social sciences, economics, agriculture and education. Malnutrition is now recognised to be both a cause and a consequence of poverty, as well as a product of certain versions of affluence.

We propose, in line with the concept of the new nutrition science ${ }^{5}$, that revitalising the movement that emerged in the mid-1990s - for a field of what has become known as public nutrition ${ }^{6,7}$ - would contribute to narrowing the gap between what nutrition scientists and professionals want to accomplish, and the health and nutrition improvements that are warranted in populations.

\section{Discussion}

\section{What is meant by public('s) nutrition}

Arising largely out of a preoccupation with the very slow progress in improving the nutrition conditions of large population segments throughout the world, public nutrition aims to address these at the population as opposed to the individual level, and through a health promotion rather than a biomedical approach, so as to hasten their resolution. Public nutrition encompasses the more traditional areas of 'public health nutrition', 'community nutrition' and 'international nutrition', but it extends beyond them.

In practice, the identification with 'public health' may frequently be too narrow for much of the action required to address the nutrition problems of concern. This is especially true with regard to food systems, even though the true spirit of public health would certainly allow for it. The resolution of nutrition problems also requires more work on public policy than is generally considered in 'community nutrition'. And finally, problems that were once associated with low-income countries now loom 
Nutrition science deals or should deal with the relationships of humans with food in all its aspects, for the production of health and well-being. Thus, the proposed new nutrition science integrates social and environmental with biological sciences; these related disciplines contribute to nutrition inasmuch as they make an explicit link between human beings, their food and their health. Public nutrition is the new nutrition science in action, with its focus on populations, problemsolving strategies, and closer links between programmes, research and training.

large in industrialised countries, and vice versa: international nutrition' does not reflect this.

Public nutrition largely shares the premises, objectives and key elements of the population health strategy ${ }^{8,9}$ and seeks to apply them more specifically to the resolution of nutrition problems. The premises of the population health strategy evolved from the world-renowned Ottawa Charter $^{10}$, expected to be reiterated in the Bangkok Charter on Health Promotion, and to be enshrined in a rights-based and a sustainable development approach which public nutrition totally shares. Sustainable nutritional improvements will only be achieved through solutions that ensure equity in implementing the right to adequate food and nutrition ${ }^{11}$. The term 'public' does reflect clear intentions: to work in the interest of the public, with the participation of the public, and with all sectors involved, not just health. Hence 'public('s) nutrition'.

\section{Assessment, analysis - and action}

Public nutrition focuses not only on assessment of the problems and analysis of their determinants, but, above all, on the concerted action required to solve them in an equitable and sustainable way. The use of this 'triple A' process has been promoted at all levels of society to help fulfil people's right to good nutrition ${ }^{12}$. It is inherent to public nutrition. An adequate assessment of the problems requires the appropriate use of nutritional epidemiology and biological knowledge of the impact of sub-optimal dietary intake. However necessary, this is not sufficient. It must be followed by an adequate analysis of the underlying determinants of the nutrition problems. They generally fall into three broad categories

\section{Food systems and food security}

The first underlying determinants of dysnutrition are those pertaining to the food environment, or food systems and food security. The global epidemic of all types of malnutrition began at a time when food production and availability had reached unprecedented high levels in history. While enough food is necessary for adequate nutrition, it is obviously not sufficient. Processes by which food is produced and distributed have considerable direct and indirect influence on what food is consumed, how and by whom, and thus on health and nutrition. The powerful forces of the private sector in the food systems impact on the health of the population in frequently unforeseen or untold ways ${ }^{13,14}$. A more thorough and global understanding of food systems and food security, of how they relate to health and nutrition, and of how they can be influenced, is seriously called for.

\section{Food and health practices}

The second underlying determinants are those that have to do with the food and health practices of communities, families and individuals and their social, psychological and cultural determinants (taking into account the food environment). The burden of the solution is still too frequently transferred to the population, lamenting on its 'resistance to education', even though the latter is seldom carried out in ways that at least consider current understanding of behaviour change.

\section{Health systems}

The third type of underlying determinants are those to do with the health systems in a given population, considering their coverage and their relevance to the nutrition issues, including the interactions between dietary intake and health status.

These broad determinants are interrelated. It is the indepth analysis of each, the priorities, and the amenability to change given existing resources and political support that can lead to appropriate action. Frequently, a combination of policies and programmes that improve the food environment, which empower individuals to adopt improved food and health practices and which decrease social and health inequities, will be called for. In a human rights-based context, with due consideration of democracy and global governance, this triple A process must be carried out in an iterative way with the participation of the population concerned and other stakeholders in civil society, the private sector and government. And for this to happen, advocacy and partnerships are indispensable.

\section{What nutrition scientists and professionals need to know}

Focusing on nutrition problems with a public nutrition lens implies knowledge and skills related not only to the more traditional area of nutrition science based on 
biological principles, but also broader social and environmental areas, as proposed in the new nutrition science $^{5}$. Nutrition science should deal with the relationship of human beings with their food, whether in its biological, socio-economic, political, ethical or environmental dimension, for the production of health and well-being. These dimensions and related disciplines need to be integrated into the theory and practice of nutrition science, to the extent that they make an explicit link between human beings, their food and their health.

Nutrition scientists and professionals thus need to know more about local foods and food systems, and their links to the global picture. It is unusual in nutrition courses to address the impact of Western food systems on local and global food security, on equity of access to food resources in low-income countries, and on environmental sustainability. The congruence of healthy eating, responsible consumption and environmental conservation is seldom examined. Among other important yet neglected issues are the illusory nutritional benefits of genetically engineered foods, and the environmental, economic and health relevance of organic farming for low-income countries as well.

Nutrition scientists and professionals also need to better understand the cultural and psychosocial factors that drive people's food and health practices $^{15}$ and to put behavioural change theories into practice ${ }^{16,17}$. Finally, they need to better understand how health systems impact on nutritional health. These demands are rather seldom fulfilled, if one takes the theses of doctoral students as an indicator (Box 1).

Beyond assessment and analyses, relevant actions require greater attention. For example, nutrition scientists and professionals should have a better knowledge of food-based approaches to improve critical micronutrient nutrition, in particular vitamin A, iron and zinc. In contrast, and in line with the biomedical approach, the prevailing strategies focus on micronutrient supplementation and, to a lesser extent, on food fortification. Such strategies may help to meet the set nutritional objectives, but they are hardly sustainable, and they show little benefit in terms of local agriculture, economy or empowerment.

In the hands of the health sector and administered according to the biological paradigm of nutrition science, supplements appear cheaper, and they are more convenient than using food. There are several impediments to agriculture- and food-based nutrition schemes, including the lack of intersectoral collaboration and limited knowledge and understanding of local food systems by nutrition scientists and professionals themselves. In a qualitative study on perceptions and opinions regarding vitamin A strategies in Sahelian countries ${ }^{18}$, nutrition scientists and professionals had little to say on the advantages and

\section{Box 1 - What nutrition doctoral students do, and don't, study}

The topics of investigation of 143 candidates for a doctoral degree in nutrition in middle- and low-income countries in 1997 were examined $^{1}$. The majority (68\%; $n=97$ ) were addressing problems in humans as opposed to animals or plants, and three-quarters of these mainly addressed problems at the population level (vs. individuals), suggesting concerns for population issues. In $15 \%$ of cases the problems addressed related to the situation of children (protein-energy malnutrition, breastfeeding, diarrhoea and so on), 35\% related to micronutrients and 30\% to chronic diseases.

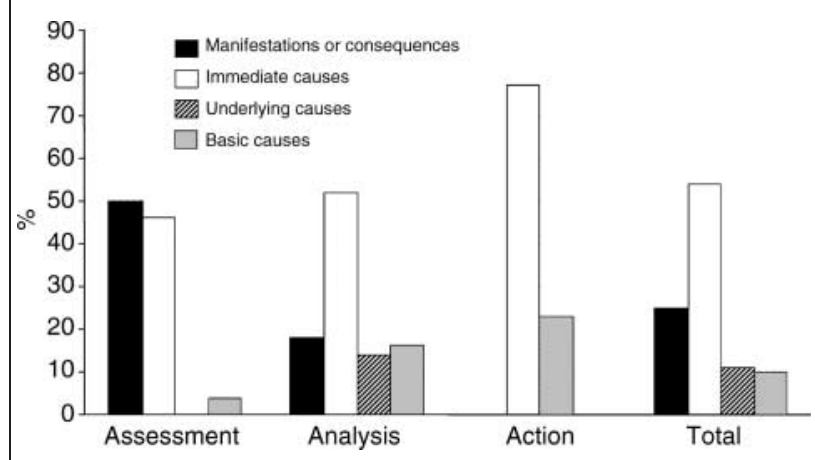

Fig. 1 Distribution (\%) of $\mathrm{PhD}$ projects in human nutrition in low-income countries by focus of study
The rest referred to a variety of topics including food security (9\%) and metabolic issues (12\%).

When these topics were further examined as to the nature of the investigation, within a conceptual framework of understanding nutrition problems, only a minority addressed issues at the level of the underlying or basic causes of the problems of interest (Fig. 1).

The majority focused on manifestations or consequences of the problem (25\%) or their immediate causes (54\%). As to whether they dealt with 'assessment', 'analysis' or 'action', only a minority (13\%) dealt with 'action' (presumably towards resolution of the problem) and mainly at the level of immediate causes. Although necessary in certain situations, action on immediate causes does not frequently lead to sustainable solutions. The future nutrition scientists in these countries largely appear to be following the current mainstream biologically based paradigm of nutrition. We were not able to carry out the same analysis in our industrial society but suspect the situation would not be very different.

\section{Reference}

1 Beaudry $M$. The practice of public nutrition: key contributors and the need for a shared understanding of the problems. Food and Nutrition Bulletin 1999; 20: $300-6$. 


\section{Box 2 - Food-based initiatives for micro-nutrition and poverty reduction: the example of red palm oil promotion in Burkina Faso ${ }^{1}$}

One teaspoon of red palm oil meets the daily safe level of vitamin A intake for a child; it also provides other antioxidants. Red palm oil has the potential to become a major vitamin A food source for a good part of Africa. This opportunity is not to be missed.

In Burkina Faso, red palm oil is produced in the western part of the country and the supply can be greatly increased. It may also provide additional income to women extracting and selling the oil. Following a 2-year pilot phase showing that it was possible to bring people to purchase the oil for nutritional benefits to women and small children, and that the approach was effective in reducing vitamin $\mathrm{A}$ deficiency, a scaling-up phase reached some 1.3 million people. Schoolchildren were targeted in addition to mothers and children under-5, and technical and managerial support was provided to several women's groups to produce and distribute red palm oil. The impact on schoolchildren's vitamin A status of 10 weeks or more of twice weekly consumption of a school meal fortified with red palm oil was impressive after one year, and similar to that of a single capsule in the year (200000 IU), with value added in terms of better adoption of red palm oil in the same communities.

The integration of red palm oil in the global micronutrient strategy of the country is now well on its way. The decision-makers now believe in the value of its promotion. There is even growing interest in developing palm plantations to meet the growing demand. There are still challenges, notably to sustain and expand its consumption by target groups, to increase its production and to strengthen the commercial distribution system, but this is an example of the potential benefits of food-based schemes.

\section{Reference}

1 Zagré N, Delpeuch F, Traissac P, Delisle H. Red palm oil as a source of vitamin A for mothers and children: impact of a pilot project in Burkina Faso. Public Health Nutrition 2003; 6: 733-42. specific means of dietary diversification for the area although they recognised the need for food-based approaches and the non-sustainability of supplementation.

\section{The need for advocacy and political will}

Even when nutrition scientists and professionals have the required knowledge, attitudes and skills, they may have limited impact on nutrition policy and programmes because they stand alone and counter-current to mainstream strategies. The latter can be strongly dependent upon donors who are also frequently ill-informed. A much greater effort therefore has to be devoted to advocating at all levels for effective programmes and policies, including food-based nutrition interventions, and to build strategic alliances for that purpose (Box 2).

Addressing the current nutrition issues requires political will. It must be seen to be in the interest of the powers in place. And so it can be. Just consider the massive investments within the UK after the spread of foot-andmouth disease, or the complete restructuring of the animal feed industry after the occurrence of around 100 deaths in the UK from the human variant of bovine spongiform encephalopathy (mad cow disease). In contrast, the death toll of malnutrition is vastly greater ${ }^{1}$. Every year the death of some 3.7 million children is attributable to general malnutrition (the majority from mild or moderate forms); of 800000 persons to lack of vitamin $A$ and an equal number to lack of iron and zinc; and 7.1 million to hypertension, 4.4 million to hypercholesterolaemia and another 2.7 million to insufficient intakes of fruits and vegetables. In the USA alone, 300000 deaths a year are attributable to obesity ${ }^{8,19}$.
And the need is not only to increase survival or life expectancy, but also disability-free life expectancy.

Meanwhile, particularly in higher-income groups, people are increasingly concerned about nutrition. In the absence of significant and coherent public policies, they become easy prey for 'quick fixes'. The food and drug industry is rapidly competing to take advantage of this new phenomenon with investments that far outweigh those of public interest institutions ${ }^{13}$. Functional foods and nutraceuticals, alongside a plethora of food and nutrition supplements, are flooding the markets and bringing huge profits for their owners without much evidence of improvements in population health. The pressures for nutrition scientists and professionals to endorse the dominant industrial strategy are sometimes very subtle but only too real ${ }^{13}$. Yes, alliances with other sectors and disciplines are necessary but they need to be carefully crafted in the interest of the public.

\section{Linking policies and programmes, research and training}

Such linkages are essential but generally weak or unplanned for. To reach a critical position on the public agenda, public nutrition needs to become a concern and priority for research, training and intervention. Currently most research and training focuses on the biological aspects of nutrition, with a sprinkling of knowledge on its underlying determinants (food systems and food security, food and health practices, health systems) and perhaps some knowledge about planning, policy-making and programming. Programmes and policies also tend to act 
primarily at the biological (or proximate determinant) level of nutrition (such as food and nutrient supplements) or sometimes on more distal determinants, but from a limited evidence base because of the paucity of relevant data from action research.

Much new knowledge is needed on key factors underlying the effectiveness of intervention strategies, and this knowledge must permeate training. Witness the successes of Thailand ${ }^{20}$ and Finland ${ }^{21}$ over the last decades, which have been well documented. Few learn about such processes during their nutrition training. There is a need for more knowledge of what is an optimal diet at various stages of the life cycle, given the local context and current knowledge, notably to develop context-specific dietary guidelines. Even problems such as the obesity epidemic are recognised to need a different approach, yet there is so far little information on the effectiveness of prevention strategies $^{22}$. As in many other population issues, it is now recognised that the application of traditional evidence hierarchies, such as those that only accept the results of randomised controlled trials as used within evidence-based medicine, is of less value in guiding policy development.
An obvious example of the optimal diet for infants as a means of preventing mortality is that of breastfeeding, often cited but not always a priority concern (Box 3).

\section{A call for nutrition action}

A major challenge of our times is the need to address simultaneously the prevention of obesity and of undernutrition. They now often coexist, and undernutrition during foetal life or early infancy may further increase the risk of chronic diseases associated with a Westernisation of food intake and physical activity patterns ${ }^{23}$. Yet, hardly any programme focuses on both. Convincing decisionmakers at the government level in low-income countries of the need to address obesity and chronic diseases is not simple. They remain considered as diseases of the rich. It even creates a 'cultural shock'24, as policies and programmes have been focusing on food insecurity, undernutrition and micronutrient deficiencies.

There is no shortage of dietitians and nutritionists in the world. The International Confederation of Dietetic Associations (ICDA) is said to represent 150000 members while not including countries like Brazil and Mexico (ICDA secretariat,

\section{Box 3 - The need to protect and support breastfeeding}

Breastfeeding should be a priority concern for nutrition scientists and professionals, and all those concerned with infant health. After all, it is the foundation of future health and development and is now accepted as the reference, the norm, against which all other infant feeding modes must be assessed.

A recent group of experts ${ }^{1}$ examined the prevention interventions for which there is sound evidence of effectiveness, and for which it is considered feasible to extend coverage to most of the population in the 42 middle- and low-income countries that account for $90 \%$ of infant mortality every year. Among the 15 prevention interventions identified, breastfeeding (exclusive for the first 6 months, and continued with appropriate complementary foods for at least a year) could save the most lives - 13\%. The next most important intervention was insecticide-treated material' which would reduce infant mortality by half of this, 7\%, and appropriate complementary feeding with $6 \%$.

What is at stake here is not the promotion of breastfeeding but rather its protection and support, such as through implementation of the International Code of Marketing of Breastmilk Substitutes ${ }^{2}$ and the Baby Friendly Hospital Initiative ${ }^{3,4}$. How many nutrition scientists and professionals are thus involved? How much is invested in such initiatives?
In contrast, the Canadian Institutes of Health Research $^{5}$ have recently provided $\$ 10$ million to complement a private company's investment to fund a large multi-site randomised controlled trial to test the ability of a hydrolysed breastmilk substitute to prevent type 1 diabetes, compared with a regular breastmilk substitute. However, the trial apparently includes limited measures to protect exclusive breastfeeding for the first few months though it is thought to be protective against diabetes (in addition to its many other benefits). Is this the evidence that is needed? What are the ethical considerations of such processes?

\section{References}

1 Jones G, Steketee RW, Black RE, Bhutta ZA, Morris SS. How many child deaths can we prevent this year? Lancet 2003; 362(9377): 65-71.

2 World Health Organization (WHO). The International Code of Marketing of Breastmilk Substitutes. Geneva: WHO, 1981.

3 Naylor AJ. Baby-Friendly Hospital Initiative. Protecting, promoting, and supporting breastfeeding in the twentyfirst century. Pediatric Clinics of North America 2001; 48(2): 475-83.

4 World Health Organization (WHO). Global Strategy for Infant and Young Child Feeding. Geneva: WHO and UNICEF (United Nations Children's Fund), 2003.

5 Canadian Institutes of Health Research. Minister McLellan launches largest pediatric clinical trial in Canada Canada to provide $\$ 10$ million to prevent the development of type I diabetes in its earliest beginnings [online]. News release, 10 June 2002. Available at http://www. cihr-irsc.gc.ca/e/8035.html 
personal communication, 2005). Brazil alone has 169 university-level schools of nutrition and dietetics with a programme of 4 years or more, and around 15500 new students a year ${ }^{25}$. Slightly more than half of the dietitians and nutritionists recently surveyed by the ICDA (2002) work in clinical nutrition ${ }^{26}$.

The large number of dietitians and nutritionists in many countries may be an untapped opportunity to move forward the vision of public nutrition, within the general context of the reconceptualised nutrition science. We propose that training be along three tracks: basic nutrition; clinical nutrition, for those who want to specialise in biology-based science; and public nutrition, for those who want to also integrate the social and environmental dimensions of nutrition.

\section{Conclusion}

It is critical to develop new knowledge, new approaches and new skills to address the nutrition challenges of our times, and to influence policy-makers through appropriate advocacy and partnerships. Identifying and developing public nutrition as the action-oriented expression of the new nutrition science will help. It will:

- Strengthen training programmes, which too frequently remain divorced from such issues.

- Encourage the funding of relevant research.

- Create a synergy to gain the momentum necessary for change.

Hence the call for public nutrition which we recently voiced in $\mathrm{Canada}^{27}$ and which we reiterate with the current call for the new nutrition science.

\section{References}

1 The World Health Report 2002. Reducing Risks, Promoting Healthy Life. Geneva: World Health Organization, 2002.

2 World Health Organization. World Cancer Report. Geneva: International Agency for Research on Cancer, 2003.

3 World Health Organization (WHO). Diet, Nutrition and the Prevention of Chronic Diseases. Report of a Joint WHO/ Food and Agriculture Organization Expert Consultation. Technical Report Series No. 916. Geneva: WHO, 2003.

4 World Health Organization (WHO). Obesity: Preventing and Managing the Global Epidemic. Report of a WHO Consultation. Technical Report Series No. 894. Geneva: WHO, 2000 (reprinted 2004).

5 The Giessen Declaration. Public Health Nutrition 2005; 8(6A): 783-6.

6 Mason J, Habicht J-P, Greaves P, Jonsson U, Kevany J, Martorell R, et al. Public nutrition. American Journal of Clinical Nutrition 1996; 63: 399-400.

7 Scrimshaw N, ed. Special Issue on Public Nutrition. Food and Nutrition Bulletin 1999; 20(3): 279-343.

8 Strategic Policy Directorate. Population Health Template: Key Elements and Actions that Define a Population Health Approach - Draft [online]. Ottawa: Population and Public Health Branch, Health Canada, 2001. Available at http://www. phac-aspc.gc.ca/ph-sp/phdd/pdf/discussion_paper.pdf

9 Edwards N. Population health: determinants and interventions. Canadian Journal of Public Health 1999; 90(1): 10-1.
10 Ottawa Charter for Health Promotion. Ottawa: World Health Organization, Health and Welfare Canada and Canadian Public Health Association, 17-21 November 1986.

11 Latham MC, Beaudry M. Globalization and inequity as determinants of malnutrition: a clear need for activism. Ecology of Food and Nutrition 2001; 40(6): 597-618.

12 United Nations Children's Fund (UNICEF). Strategy for Improved Nutrition of Children and Women in Developing Countries. A UNICEF Policy Review. New York: UNICEF, 1990.

13 Nestle M. Food Politics: How the Food Industry Influences Nutrition and Health. Berkeley, CA: University of California Press, 2002.

14 Lang T, Heasman M. Food Wars - The Global Battle for Mouths, Minds and Markets. London: Earthscan, 2004.

15 Engle PL, Bentley M, Pelto G. The role of care in nutrition programmes: current research and a research agenda. Proceedings of the Nutrition Society 2000; 59(1): 25-35.

16 Achterberg C, Miller C. Is one theory better than another in nutrition education? A viewpoint: more is better. Journal of Nutrition Education and Behavior 2004; 36(1): 40-2.

17 Daneault S, Beaudry M, Godin G. Psychosocial determinants of the intention of nurses and dietitians to recommend breastfeeding. Canadian Journal of Public Health 2004; 95(2): 151-4.

18 Delisle H. Food diversification strategies are neglected in spite of their potential effectiveness: why is it so and what can be done?. In: Brouwer I, Traoré A, Trèche S, eds. Proceedings of the 2nd International Workshop on Foodbased Approaches for a Healthy Nutrition in West Africa. Ouagadougou: Presse Universitaire, 2004; 303-16.

19 US Department of Health and Human Services (DHHS). The Surgeon General's Call to Action to Prevent and Decrease Overweight and Obesity. Rockville, MD: DHHS, Public Health Service, Office of the Surgeon General, 2001.

20 Tontisirin K, Winichagoon K. Community-based programmes: success factors for public nutrition derived from the experience of Thailand. Food and Nutrition Bulletin 1999; 20(3): 315-22.

21 Nissinen A, Berrios X, Puska P. Community-based noncommunicable disease interventions: lessons from developed countries for developing ones. Bulletin of the World Health Organization 2001; 79(10): 963-70.

22 Swinburn B, Gill T, Kumanyika S. Obesity prevention: a proposed framework for translating evidence into action. Obesity Reviews 2005; 6(1): 23-33.

23 Delisle H, Ghadirian P, Shatenstein B, Strychar I. Evidence and implications for research and action: a summary. In: International Workshop on Early Nutrition Influences on Obesity, Diabetes and Cardiovascular Disease, 6-9 June 2004. Montreal Proceedings: Maternal \& Child Nutrition 2005; 1(3): 215-21.

24 Solomons N. Program and policy issues related to promoting positive early nutritional influences to prevent obesity, diabetes and cardiovascular disease in later life: a developing countries view. In: International Workshop on Early Nutrition Influences on Obesity, Diabetes and Cardiovascular Disease, 6-9 June 2004. Montreal Proceedings: Maternal \& Child Nutrition 2005; 1(3): 203-14.

25 De Araújo Calado CL. A expansão dos cursos de nutrição no Brasil e a nova lei de diretrizes e bases - LDB [online]. Conselho Federal de Nutricionistas (CFN), 2003. Available at http://www.cfn.org.br/variavel/destaque/expansao.doc. Accessed July 2005.

26 ICDA. Workshop on definitions, education, standards and practice in dietetics. Dietetics Around the World-Newsletter of the International Confederation of Dietetic Associations 2004; 11(2).

27 Beaudry M, Hamelin A-M, Delisle H. Public nutrition: an emerging paradigm. Canadian Journal of Public Health 2004; 95(5): 375-7. 